\title{
Kömür hazırlama tesis artıklarının koagülasyon ile susuzlandırılmasında farklı koagülant tiplerinin etkisinin araştırılması
}

\author{
Mehmet Faruk ESKİBALCI*, Mehmet Furkan ÖZKAN \\ İstanbul Üniversitesi Müh. Fak. Maden Mühendisliği Bölümü, Avcılar Kampüsü, İstanbul \\ Geliş Tarihi (Recived Date): 06.02.2018 \\ Kabul Tarihi (Accepted Date): 25.12.2018
}

\section{Özet}

Bu çalışmada, kömür hazırlama tesis atık sularının koagülasyon ile çöktürülmesinde farklı tip koagülantların çöktürme verimi üzerindeki etkisi araştırılmış ve elde edilen sonuçlar birbirleriyle mukayese edilerek en uygun koagülant tipi belirlenmeye çalışılmıştır. Koagülasyon testlerinde koagülant tipi ve miktarı, ortam pH'sı, karıştırma süresi ve hızı gibi parametreler test edilmiştir. Her bir deney sonrası süspansiyonun türbiditesi ölçülerek koagülasyon verimleri hesaplanmıştır. Demir sülfat, alüminyum sülfat ve demir klorür ile yapılan koagülasyon deneylerinden elde edilen sonuçlara göre koagülasyon verimlerinin sırastyla; \%67.21, \%88.71 ve \%94 olduğu tespit edilmiştir. Deneyler sırasında koagülantların tüketim miktarlarından yola çıkarak işlem maliyetleri de tespit edilmiştir. Tüm bu sonuçlar ışığında demir klorürün diğer koagülantlara göre daha verimli ve ekonomik olduğu belirlenmiştir.

Anahtar kelimeler: Kömür, koagülasyon, koagülant, demir sülfat, demir klorür.

\section{Investigation of the effects of different coagulant types for dewatering of coal plant tailings}

\begin{abstract}
Abstret
In this study, the effects of different types of coagulants were investigated on the precipitation of coal preparation plant wastewaters and the results were compared with each other to determine the most suitable coagulant type. In coagulation tests, parameters such as type and amount of coagulant, media $\mathrm{pH}$, mixing time and speed

\footnotetext{
*Mehmet Faruk ESKIBBALCI, eskibal@istanbul.edu.tr, http://orcid.org/0000-0001-9163-7899

Mehmet Furkan ÖZKAN, ozkanmfurkan@ yahoo.com, https://orcid.org/0000-0001-6489-2229
} 
were tested. After each test, the turbidity of the suspension was measured and the coagulation efficiencies were calculated. The results of coagulation experiments with iron sulphate, aluminum sulphate and ferric chloride showed that the coagulation efficiencies were; $67.21 \%, 88.71 \%$ and $94 \%$, respectively. During the experiments, the costs of the coagulants have been determined from the consumption amounts of the coagulants. All these results indicate that iron chloride is more efficient and economical than other coagulants.

Keywords: Coal, coagulation, coagulant, iron sulphate, iron chloride.

\section{Giriş}

Linyit, ısıl değeri düşük, barındırdığı kül ve nem miktarı fazla olduğu için genellikle termik santrallerde yakıt olarak kullanılan bir enerji hammaddesidir. Son yıllarda arama faaliyetleri sonucunda ülkemiz linyit rezervleri de önemli ölçüde arttırılmıştır. Ülkemiz linyit rezerv ve üretim miktarları açısından dünya ölçeğinde orta düzeyde değerlendirilebilir. Toplam dünya linyit kömür rezervinin yaklaşık \%3.2'si ülkemizde bulunmaktadır. Bununla birlikte linyitlerimizin büyük kısmının 1sıl değeri düşük olduğundan termik santrallerde kullanımı ön plana çıkmaktadır. Ülkemiz linyit rezervinin yaklaşık \%46'sı Afşin-Elbistan havzasında bulunmaktadır [1].

Üretilen kömürlerin kullanılmadan önce tesislerde bir dizi işlemden geçmesi gerekmektedir. Bunlar arasında, yıkama, yaş eleme, çöktürme, susuzlandırma vb. bulunmaktadır [2]. Kömür hazırlama tesislerinde uygulanan proseslere bağlı olarak içerisinde çok ince boyutta mineral maddelerden oluşan (kömür, kil, kuvars vb.) atık sular ortaya çıkmaktadır. Bu atık suların doğrudan çevreye bırakılması önemli çevre problemlerine yol açmaktadır. Bunu önlemek için katı-sıvı ayırımı yaparak mümkün olduğunca katı içeriği düşük su elde etmek ve bu suyunda tesiste tekrar kullanılmasını sağlamak önem arz etmektedir. Susuzlandırma işlemleri cevher hazırlama ve kömür yıkama tesislerinde en maliyetli işlemlerden birisidir [3]. Susuzlandırma işlemi tikiner denilen büyük havuzlarda flokülasyon ve koagülasyon gibi klasik yöntemler ile uygulanabilmektedir [4-5]. Bu her iki yöntemde de taneciklerin çökmesini hızlandırıcı ilave kimyasallar kullanılmaktadır. Ancak bu işlem, süspansiyon içerisindeki farklı şekil, boyut ve ağırlıktaki tanelerin varlığı, her bir tanenin farklı koloidal davranışı ve ortamdan kaynaklanan değişkenler nedeniyle karmaşık bir yapı arz etmektedir [6-8].

Flokülasyon ve koagülasyon yöntemleri aynı amaçla kullanılmasına karşın aralarındaki fark, koagülasyonda süspansiyona iyon ilavesi ile katı-sıvı ara yüzeyinde oluşan elektriksel yüklerin karşılıklı olarak azaltılması sonucu itme kuvvetlerinin etkinliğinin yitirilmesi iken, flokülasyonda çözeltiye yüksek molekül ağırlıklı polimer ilavesiyle tanelerin salkımlaştırılmasını sağlamaktır [7]. Süspansiyon içerisindeki tanelerin belli bir elektrik yükleri vardır. $\mathrm{Bu}$ yükün işareti ve miktarı tanelere göre değişiklik gösterebilmektedir ve bu taneler arası etkileşimde önemli rol oynamaktadır [9].

Bu çalışmada özel bir madencilik firmasının kömür hazırlama tesisinden alınan atık sularının koagülasyonunda farklı tip koagülantların etkisi araştırılmış, ayrıca verim ve maliyet bakımından da bir birbirleri ile mukayese edilmiştir. 


\section{Malzeme ve metod}

\subsection{Malzemeler}

Bu çalışmada kullanılan kömür atık su numunesi Marmara bölgesi Tekirdağ ili sınırları içerisinde faaliyet gösteren özel bir madencilik firmasından elde edilmiştir. Kömür hazırlama tesis atıksu numunelerinin çöktürüldüğü tikiner giriş ünitesinden pülp halinde alınan numuneler laboratuara 20 şer kg'lık plastik bidonlar içerisinde getirilmiştir.

Koagülasyon deneylerinde koagülant olarak piyasada yaygın olarak bulunan alüminyum sülfat $\left[\mathrm{Al}_{2}\left(\mathrm{SO}_{4}\right)_{3} \cdot 16 \mathrm{H}_{2} \mathrm{O}\right.$ ], demir sülfat $\left[\mathrm{FeSO}_{4} .7 \mathrm{H}_{2} \mathrm{O}\right]$ ve demir klorür $\left[\mathrm{FeCl}_{3} .6 \mathrm{H}_{2} \mathrm{O}\right.$ ] (analitik saflıkta) kullanılmıştır.

Alüminyum sülfat "alüm" olarak ifade edilen ve suda kolayca çözünebilen bir bileşiktir. Alüm ile koagülasyon düşük $\mathrm{pH}^{\prime} l a r d a ~(\mathrm{pH}<4)$ genellikle yük nötralizasyonu ile gerçekleşirken nötral pH'larda ( $\mathrm{pH}$ 6-8) sıyırma mekanizması ile gerçekleşmektedir. Çünkü düşük $\mathrm{pH}$ 'larda süspansiyonda bol miktarda serbest $\mathrm{Al}^{+3}$ iyonları bulunurken orta ve yükssek pH'larda hidroksilli $\mathrm{Al}$ bileşiği olan $\mathrm{Al}(\mathrm{OH})_{3}$ çökeleği oluşmaktadır. Alümün sudaki hidrolizi sonucu oluşan alüminyum hidroksit genellikle $\mathrm{Al}_{2} \mathrm{O}_{3} \cdot \mathrm{xH}_{2} \mathrm{O}$ formundadır ve amfoterdir. $\mathrm{FeSO}_{4} \cdot 7 \mathrm{H}_{2} \mathrm{O}$ formülü ile gösterilen demir sülfat, endüstriyel atık suların arıtılmasında ve zirai faaliyetlerde gübre olarak kullanılan bir koagülanttır. Su ile etkin reaksiyonu $\mathrm{pH}$ 5-10 aralığında olmaktadır. $\mathrm{FeCl}_{3} \cdot 6 \mathrm{H}_{2} \mathrm{O}$ formülü ile gösterilen demir klorürde demir +3 değerliklidir. Demir klorürün su ile etkin reaksiyonu pH 6-9 aralığında sağlanmaktadır. Çözelti formu korozif özeliğe sahiptir. $\mathrm{FeCl}_{3}$ etkili bir koagülant olmasının yanı sıra suda hidrolizi sonucu oldukça aktif ve geniş bir yüzey alanına sahip $\mathrm{Fe}(\mathrm{OH})_{3}$ flokları oluşturmaktadır.

Tesisten alınan proses suyu ve laboratuarda kullanılan şebeke suyunun kimyasal analizleri yapılarak katyon ve anyon değerleri belirlenmiştir. Atık numunesinin tane boyut dağılım analizi Malvern Mastersize 2000 model cihaz ile, kimyasal analizi Axios SST-Max XRF cihazı ile ve mineralojik analizi ise Rigaku D/Max-2200/PC XRD cihazı ile yapılmıştır. Isıl değer analizleri de yapılarak numunenin alt ve üst isıl değerleri tespit edilmiştir.

Farklı iyon konsantrasyonlarının atık numunesinin yüzey yükü üzerinde bir etkisinin olup olmadığını araştırmak için saf su, proses suyu ve şebeke suyu içerisinde zeta potansiyeli ölçümleri Brookhaven Zetaplus, USA marka cihaz kullanılarak $1 \%$ katı oranında gerçekleştirilmiştir.

\subsection{Metod}

Tesisten gelen numunelerin PKO' nını belirlemek için öncelikle katı-sıvı ayırımı yapılarak serbest su uzaklaştırılmış ve daha sonra doğal kurutma ile tüm malzeme kurutularak homojen hale getirilmiştir. Tesisten getirilen numunenin PKO'nı \%3 olarak tespit edilmiş ve yapılan tüm deneylerde bu oran baz alınarak 1 lt'lik kap içerisine $30 \mathrm{gr}$ kurutulmuş atık numunesi şebeke suyu ile birlikte konulup karıştırılmış ve deney numuneleri hazırlanmıştır.

Çoğu kolloidal maddeler negatif yüzey yüklerine sahip olduklarından dolayı çöktürme işlemi genellikle koagülant olarak +3 değerlikli alüminyum ve demir kullanılarak gerçekleştirilmektedir. Bu elementlerin sülfat veya klorür bileşikleri suya eklendiğinde sudaki alkalinite ile birleşerek metal hidroksitleri oluşturmaktadır. Oluşan metal 
hidroksitler normal pH değerlerinde az çözünen ve çökebilen özelliğe sahiptirler. Koagülasyon deneylerinde reaktif tipi ve miktarı, ortam pH'sı karıştırma süresi ve hızı gibi farklı işletme parametrelerinin süspansiyonun çökme davranışı üzerindeki etkileri araştırılmıştır.

Koagülasyon deneyleri 150x90x85 mm boyutlarında $1150 \mathrm{~cm}^{3}$ hacimli pleksiglastan imal edilmiş bir reaktör içerisinde gerçekleştirilmiştir. Her bir deney öncesinde atık süspansiyonları bir manyetik karıştırıcı yardımıyla 500 devir/dk hızla $30 \mathrm{dk}$ boyunca karıştırılarak homojen hale getirilmiştir.

Koagülasyon deneylerinde her deneyin $10,20,30$ ve 60 . dakikalarında süspansiyon yüzeyinin $2 \mathrm{~cm}$ aşağısından alınan numunelerin bulanıklık değerleri türbidimetre ile NTU cinsinden ölçülmüştür. Koagülasyon deneyleri için uygulanan parametreler Tablo 1 'de görülmektedir.

Tablo 1: Koagülasyon deney parametreleri.

\begin{tabular}{|c|c|c|c|c|}
\hline Koagülant & $\begin{array}{c}\text { Karıștırma } \\
\text { Süresi } \\
(\mathrm{dk})\end{array}$ & $\begin{array}{l}\text { Karıştırma Hızı } \\
\text { (dev./dk) }\end{array}$ & $\begin{array}{l}\text { Dozaj } \\
\left(\mathrm{cm}^{3}\right)\end{array}$ & $\mathrm{pH}$ \\
\hline $\mathrm{AlSO}_{4}$ & $\begin{array}{l}0.67-1-2.5-5- \\
10\end{array}$ & $\begin{array}{l}100-150-200-250- \\
300\end{array}$ & $\begin{array}{l}10-15-20-25- \\
30\end{array}$ & $\begin{array}{l}\left.\text { 6-7.56(doğ.pH* } \mathrm{H}^{*}\right) \\
8-9\end{array}$ \\
\hline $\mathrm{FeSO}_{4}$ & $2.5-5-10-15-20$ & $\begin{array}{l}150-200-250-300- \\
350\end{array}$ & $\begin{array}{l}10-15-20-25- \\
30\end{array}$ & $\begin{array}{l}\text { 6-7.65(doğ.pH*)- } \\
8-9\end{array}$ \\
\hline $\mathrm{FeCl}_{3}$ & $\begin{array}{l}1.15-2.5-5-10- \\
15\end{array}$ & $\begin{array}{l}100-150-200-250- \\
300\end{array}$ & $\begin{array}{l}10-15-20-25- \\
30\end{array}$ & $\begin{array}{l}\text { 6-7.56(doğ.pH*)- } \\
8-9\end{array}$ \\
\hline
\end{tabular}

Deney sonuçları yapılan türbidite ölçümleri ile değerlendirilmiştir. Türbitide uzaklaştırma verimi Formül 1 ile hesaplanmıştır;

$R(\%)=\frac{T_{0}-T_{t}}{T_{0}} \times 100$

Burada; $T_{0}$, koagülasyon işlemleri öncesinde süspansiyonun ilk türbiditesi; $T_{t}$, belirlenmiş çökme süresi sonundaki türbiditesidir.

\section{Bulgular}

Tesisten alınan proses suyu ve laboratuarda kullanılan şebeke suyunun yapılan kimyasal analiz sonuçları Tablo 2'de verilmiştir. Test sonuçlarına bakıldığında proses suyu içerisindeki katyonların sodyum, magnezyum ve kalsiyum olduğu görülürken anyon olarak da büyük oranda sülfat ve klor'un varlığı görülmektedir.

Malvern Mastersize 2000 model cihaz ile yapılan atık numunesinin tane boyut dağılım analizi sonucunda numunenin ortalama tane boyutu $\left(\mathrm{d}_{50}\right) 45$ mikron olarak tespit edilmiştir. Axios SST-Max XRF cihazı ile yapılan numunenin kimyasal analiz sonuçları Tablo 3'de verilmiştir. Yapılan analiz sonucunda numunenin kızdırma 
kaybının \%30 olduğu tespit edilmiştir. Bu sonuç numune içerisinde önemli miktarda karbonlu bileşik yani kömür bulunduğunu göstermektedir.

Tablo 2: Proses suyu ve şebeke suyunun kimyasal analiz sonuçları.

\begin{tabular}{|c|l|c|c|}
\hline \multicolumn{2}{|l|}{ Anyon/Katyon Tipi } & $\begin{array}{c}\text { Proses } \\
\text { Suyu,ppm }\end{array}$ & Şebeke Suyu,ppm \\
\hline \multirow{4}{*}{ Anyonlar } & Florür & 0.1 & 0.1 \\
\cline { 2 - 4 } & Klorür & 93.5 & 29.1 \\
\cline { 2 - 4 } & Bromür & 0.1 & 0.1 \\
\cline { 2 - 4 } & Nitrat & 0.1 & 1.8 \\
\cline { 2 - 4 } & Sülfat & 1537.8 & 41.7 \\
\hline \multirow{3}{*}{ Katyonlar } & Sodyum & 291.0 & 19.8 \\
\cline { 2 - 4 } & Potasyum & 17.6 & 2.5 \\
\cline { 2 - 4 } & Magnezyum & 209.4 & 6.4 \\
\cline { 2 - 4 } & Kalsiyum & 111.9 & 45.2 \\
\hline
\end{tabular}

Tablo 3: Numunenin kimyasal analizi

\begin{tabular}{|l|c|c|c|c|c|c|c|c|c|}
\hline Bileşik & $\mathrm{SiO}_{2}$ & $\mathrm{Al}_{2} \mathrm{O}_{3}$ & $\mathrm{Fe}_{2} \mathrm{O}_{3}$ & $\mathrm{MgO}$ & $\mathrm{CaO}$ & $\mathrm{K}_{2} \mathrm{O}$ & $\mathrm{TiO}_{2}$ & $\mathrm{Na}_{2} \mathrm{O}$ & K.K. \\
\hline$\%$ & 38.07 & 13.23 & 7.63 & 3.02 & 2.85 & 2.11 & 0.53 & 0.20 & 30 \\
\hline
\end{tabular}

Rigaku D/Max-2200/PC XRD cihazı ile yapılan mineralojik analiz sonucunda numune içerisinde; linyit, kuvars, muskovit, montmorillonit, klorit, serpantin, kalsit ve dolomit gibi minerallerin varlığı tespit edilmiştir. Isıl değer analizleri de yapılarak numunenin alt ve üst 1sıl değerleri belirlenmiş̧tir. Alt ve üst 1 sıl değerleri sırasıyla $802 \mathrm{kcal} / \mathrm{kg}$ ve $820 \mathrm{kcal} / \mathrm{kg}$ olarak bulunmuştur. Atık numunesinin saf su, proses suyu ve şebeke suyu ile yapılmış zeta potansiyeli ölçüm sonuçları Tablo 4'de verilmiştir.

Tablo 4: Kömür atık numunesinin zeta potansiyeli değerleri

\begin{tabular}{|l|c|c|c|}
\hline \multicolumn{1}{|c|}{ Su Tipi } & $\mathrm{pH}($ doğal $)$ & $\begin{array}{c}\text { Zeta Potansiyeli } \\
(\mathrm{mV})\end{array}$ & İletkenlik $(\mathrm{mS} / \mathrm{cm})$ \\
\hline Saf su & 6.09 & -17.53 & 0.5 \\
\hline Şebeke suyu & 7.8 & -22.12 & 1.3 \\
\hline Proses Suyu & 7.66 & -24.17 & 6.4 \\
\hline
\end{tabular}

Tablo 4'de görüldüğü gibi atık numuneleri her üç su içerisinde negatif yüzey yüküne sahiptir. Deneylerde kullanılan süspansiyonların iletkenlik değerlerine bakıldığında proses suyu içerisinde diğerlerine göre daha fazla iletkenlik ölçülmüştür. Bu sonuçlar proses suyunun diğerlerine göre oldukça tuzlu olduğunu göstermektedir. Proses su içerisinde elde edilen negatif yük özellikle sülfat iyonunun minerallerin zeta potansiyelleri üzerindeki etkisini açıklamaktadır. 


\subsection{Alüminyum sülfat $\left[\mathrm{Al}_{2}\left(\mathrm{SO}_{4}\right)_{3} .16 \mathrm{H}_{2} \mathrm{O}\right]$ ile yapılan deneyler}

Alüminyum sülfat ile yapılan koagülasyon deney sonuçları Şekil 1'de verilmiştir.

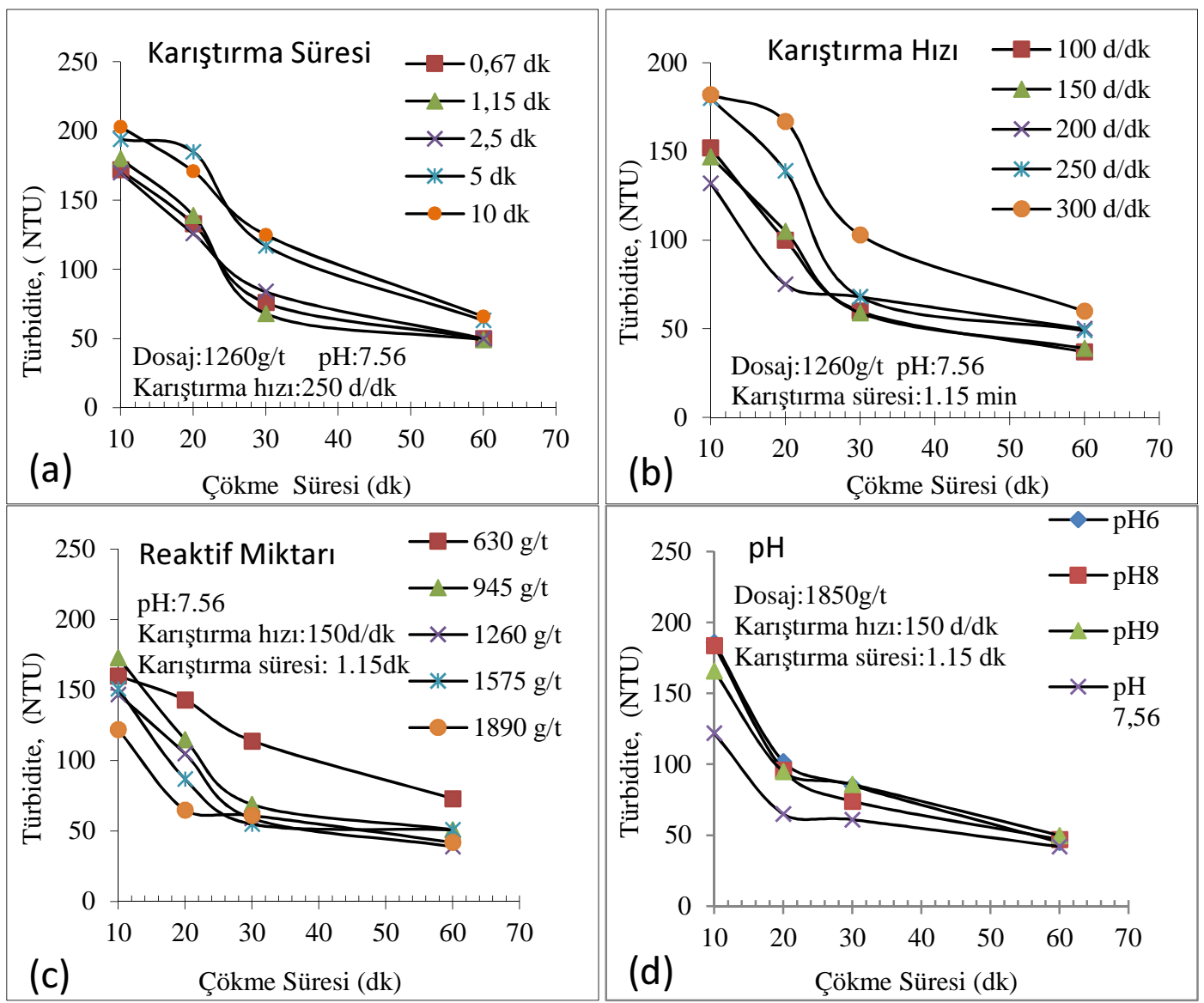

Şekil 1: Alüminyum sülfat ile yapılan deneylerde a)Karıștırma süresi b)Karıștırma hızı c)Reaktif miktarı d)Ortam pH'sının koagülasyona etkisi

Optimum karıştırma süresini belirlemek için yapılan ilk aşama deneylerde diğer parametreler olan reaktif miktarı, $\mathrm{pH}$ ve karıştırma hızı sırasıyla $1260 \mathrm{~g} / \mathrm{ton}, 7.56$ (doğal $\mathrm{pH})$ ve $250 \mathrm{~d} / \mathrm{dk}$ olarak sabit tutulmuştur. Şekil 1(a) incelendiğinde süspansiyonun karıştırma süresi arttıkça ölçülen bulanıklık değerlerinde bir artış gözlendiği, en düşük bulanıklık sonuçlarının ise $1.15 \mathrm{dk}$ 'lık karıştırma süresi sonrasında yapılan deneylerden elde edildiği görülmüştür. Optimum karıştırma hızını belirlemek için yapılan deneylerde diğer parametreler olan karıştırma süresi, reaktif miktarı ve pH sırasıyla $1.15 \mathrm{dk}, 1260 \mathrm{~g} /$ ton ve 7.56(doğal pH) olarak sabit tutulmuştur. Şekil 1(b) incelendiğinde süspansiyonun karıștırma hızı artığında bulanıklık değerlerinde de bir artış olduğu, en iyi sonuçların ise $150 \mathrm{devir} / \mathrm{dk}$ karıştırma hızı ile yapılan deneylerden elde edildiği görülmüştür. Optimum reaktif miktarını belirlemek için yapılan deneylerde diğer parametreler olan karıştırma süresi, karıştırma hızı ve pH sırasıyla $1.15 \mathrm{dk}, 150 \mathrm{~d} / \mathrm{dk}$ ve $7.56(\mathrm{doğal} \mathrm{pH})$ olarak sabit tutulmuştur. Şekil 1(c)'yi incelediğimizde reaktif miktarı arttıkça farklı çökme sürelerinde elde edilen bulanıklık değerlerinin düştüğü, en iyi sonuçların $1890 \mathrm{~g} /$ ton reaktif miktarının kullanıldığ deneylerden elde edildiği tespit edilmiştir. Optimum pH'yı belirlemek için yapılan deneylerde diğer parametreler olan karıştırma süresi, karıştırma hızı ve reaktif miktarı sırasıyla $1.15 \mathrm{dk}, 150 \mathrm{~d} / \mathrm{dk}$ ve $1890 \mathrm{~g} /$ ton olarak sabit tutulmuştur. Şekil 1(d) 
incelendiğinde $\mathrm{pH}$ 7.56(doğal $\mathrm{pH})$ da yapılan deneylerde en düşük bulanıklık sonuçlarının alındığı, ortamın asidik veya bazik olması durumunda reaktifin koagüle etme özelliğinin azaldığı tespit edilmiştir.

Alüminyum sülfat ile yapılan deneylerden elde edilen veriler 1şı̆̆ında optimum deney şartlarının $1.15 \mathrm{dk}$ karıştırma süresi, $150 \mathrm{devir} / \mathrm{dk}$ karıștırma hızı, $1890 \mathrm{~g} /$ ton reaktif miktarı ve doğal $\mathrm{pH}(\mathrm{pH}=7.56)$ olduğu, bu koşullarda yapılan deney ile süspansiyonun türbiditesi başlangıç değeri olan 551 NTU'dan 65 NTU değerine \%88.71 koagülasyon verimi ile düşürüldüğü tespit edilmiştir.

\subsection{Demir sülfat [ $\left.\mathrm{FeSO}_{4} .7 \mathrm{H}_{2} \mathrm{O}\right]$}

Demir sülfat ile yapılan koagülasyon deney sonuçları Şekil 2'de verilmiştir.

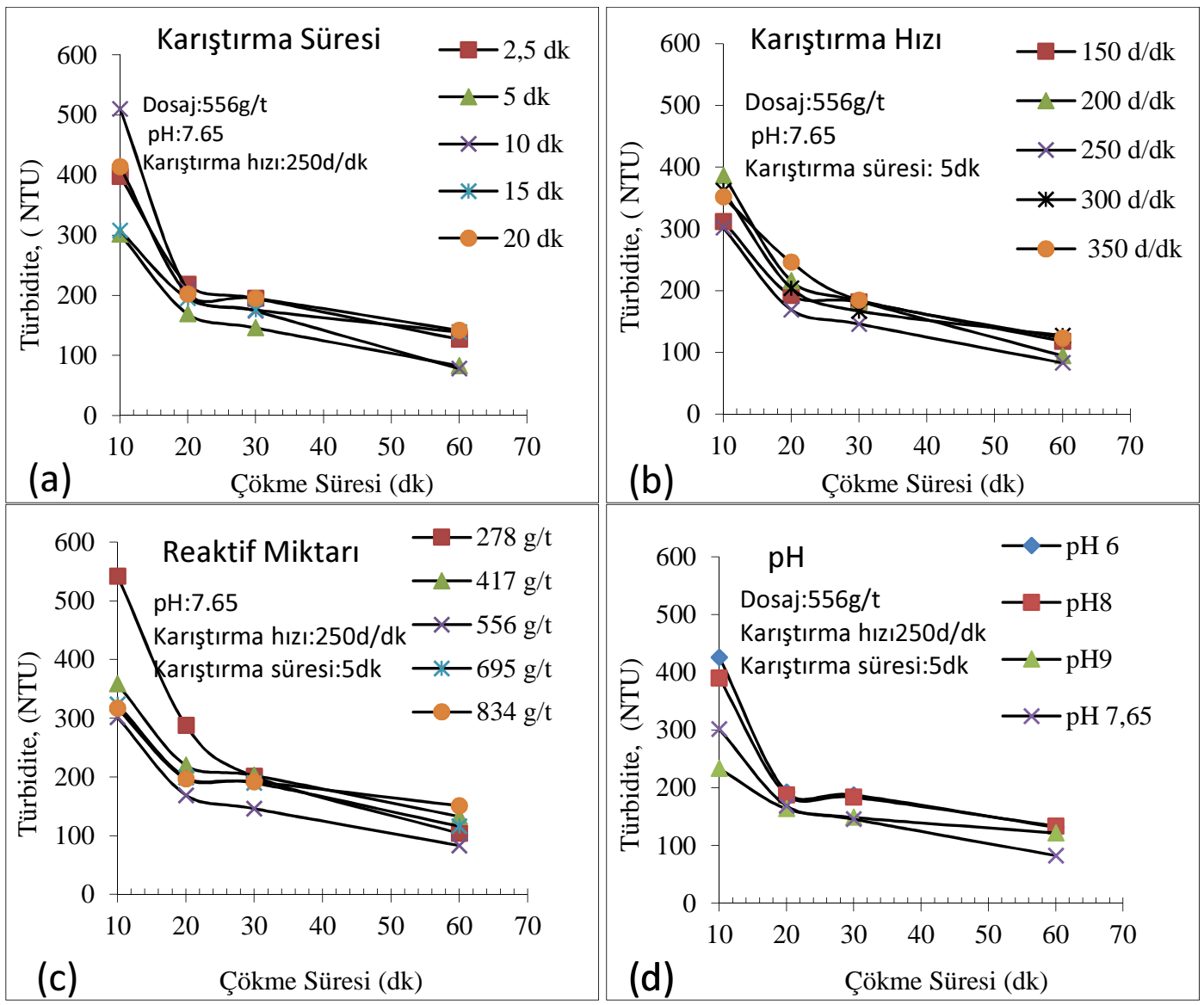

Şekil 2: Demir sülfat ile yapılan deneylerde a)Karıştırma süresi b)Karıştırma hızı c)reaktif miktarı d)Ortam pH'sının koagülasyona etkisi

Optimum karıştırma süresini belirlemek için yapılan ilk aşama deneylerde diğer parametreler olan reaktif miktarı, pH ve karıştırma hızı sırasıyla $556 \mathrm{~g} /$ ton, 7.65(doğal $\mathrm{pH}$ ) ve $250 \mathrm{~d} / \mathrm{dk}$ olarak sabit tutulmuştur. Şekil 2(a) incelendiğinde süspansiyonun karıştırma süresi arttıkça farklı çökme sürelerinde ölçülen bulanıklık değerlerinde bir artış gözlendiği, en düşük bulanıklık değerlerinin ise $5 \mathrm{dk}$ 'lık karıştırma süresi sonrasında yapılan deneylerden elde edildiği görülmüştür. Optimum karıştırma hızını belirlemek için yapılan deneylerde diğer parametreler olan karıștırma süresi, reaktif miktarı ve pH sırasıyla $5 \mathrm{dk}, 556 \mathrm{~g} / \mathrm{ton}$, ve 7.65(doğal $\mathrm{pH}$ ) olarak sabit tutulmuştur. Şekil 2(b) incelendiğinde en iyi sonuçların 250 devir/dk karıştırma hızı ile yapılan 
deneylerden elde edildiği görülmüştür. Optimum reaktif miktarını belirlemek için yapılan deneylerde diğer parametreler olan karıştırma süresi, karıştırma hızı ve pH sirasıyla $5 \mathrm{dk}, 250 \mathrm{~d} / \mathrm{dk}$ ve $7.65(\mathrm{doğal} \mathrm{pH}$ ) olarak sabit tutulmuştur. Şekil 2(c)'yi incelediğimizde en iyi sonuçların $20 \mathrm{~cm}^{3}$ (556 g/ton) reaktif miktarının kullanıldığ deneylerden elde edildiği tespit edilmiştir. Optimum pH'yı belirlemek için yapılan deneylerde ise diğer parametreler olan karıștırma süresi, karıştırma hızı ve reaktif miktarı sırasıyla $5 \mathrm{dk}, 250 \mathrm{~d} / \mathrm{dk}$ ve $556 \mathrm{~g} /$ ton olarak sabit tutulmuştur. Şekil 2(d) incelendiğinde ise $\mathrm{pH} 7.65(\mathrm{doğal} \mathrm{pH})$ da yapılan deneylerde en iyi sonuçların alındığı tespit edilmiştir.

Demir sülfat ile yapılan deneylerde elde edilen veriler 1 şığında optimum deney şartlarının; $5 \mathrm{dk}$ karıştırma süresi, $250 \mathrm{devir} / \mathrm{dk}$ karıştırma hızı, $20 \mathrm{~cm}^{3}$ (556 g/ton) reaktif miktarı ve $\mathrm{pH} 7.65($ doğal $\mathrm{pH}$ ) olduğu tespit edilmiştir. Bu koşullarda yapılan deney ile süspansiyonun türbiditesi başlangıç değeri olan 555 NTU'dan 83 NTU değerine \%85.05 koagülasyon verimi ile düşürülmüştür.

\subsection{Demir klorïr $\left[\mathrm{FeCl}_{3} .6 \mathrm{H}_{2} \mathrm{O}\right]$}

Demir sülfat ile yapılan koagülasyon deney sonuçları Şekil 3'de verilmiştir.

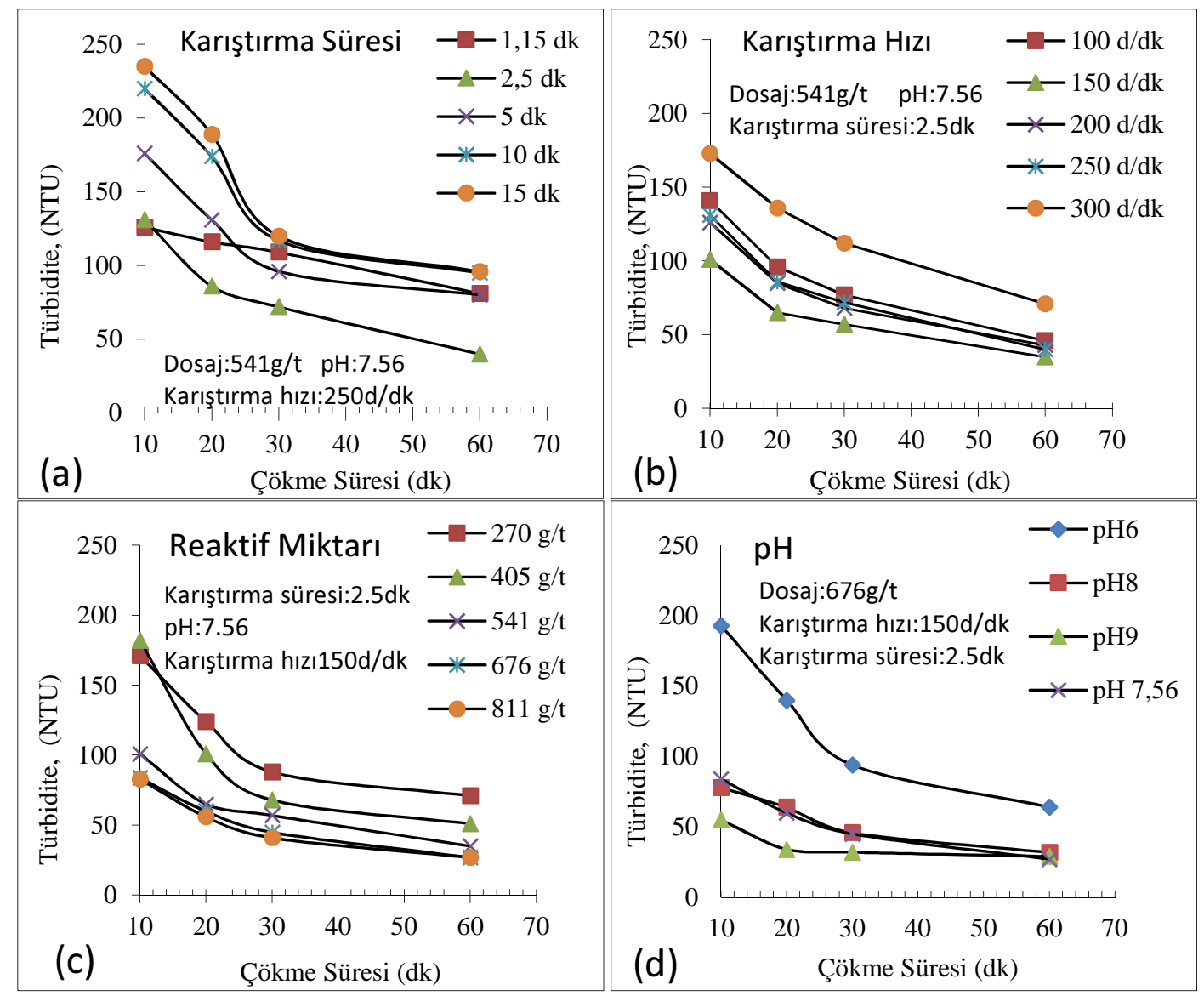

Şekil 3: Demir klorür ile yapılan deneylerde a)Karıştırma süresi, b)Karıştırma hızı, c)reaktif miktarı, d)Ortam pH'sının koagülasyona etkisi

Optimum karıștırma süresini belirlemek için yapılan ilk aşama deneylerde diğer parametreler olan reaktif miktarı, $\mathrm{pH}$ ve karıştırma hızı sırasıyla $541 \mathrm{~g} /$ ton, 7.56(doğal $\mathrm{pH})$ ve $250 \mathrm{~d} / \mathrm{dk}$ olarak sabit tutulmuştur. Şekil 3(a) incelendiğinde süspansiyonun 
karıştırma süresi arttıkça farklı çökme sürelerinde ölçülen bulanıklık değerlerinde bir artış gözlendiği, en düşük bulanıklık sonuçların 2.5 dk'lık karıştırma süresi sonrasında yapılan deneylerden elde edildiği görülmüştür. Optimum karıştırma hızını belirlemek için yapılan deneylerde diğer parametreler olan karıştırma süresi, reaktif miktarı ve $\mathrm{pH}$ sirasıyla 2.5dk, $541 \mathrm{~g} /$ ton ve 7.56(doğal pH) olarak sabit tutulmuştur. Şekil 3(b) incelendiğinde karıştırma hız arttıkça bulanıklık değerlerinde abir artış olduğu en düşük bulanıklık sonuçlarının ise 150 devir/dk karıştırma hızı ile yapılan deneylerden elde edildiği görülmüştür. Optimum reaktif miktarını belirlemek için yapılan deneylerde diğer parametreler olan karıştırma süresi, karıştırma hızı ve $\mathrm{pH}$ sırasıyla $2.5 \mathrm{dk}, 150 \mathrm{~d} / \mathrm{dk}$ ve 7.56(doğal $\mathrm{pH}$ ) olarak sabit tutulmuştur. Şekil 3(c)'yi incelediğimizde reaktif miktarı arttıkça bulanıklık değerlerinde bir düşme olduğu, $25 \mathrm{~cm}^{3}$ (676 g/ton) ve $30 \mathrm{~cm}^{3}$ (811 g/ton) reaktif miktarlarının en iyi sonuçları verdiği tespit edilmiş, maliyet göz önüne alınarak bundan sonraki deneylerde $25 \mathrm{~cm}^{3}(676 \mathrm{~g} / \mathrm{ton})$ değerinin optimum reaktif miktarı olarak alınmasına karar verilmiştir.

Optimum pH'yı belirlemek için yapılan deneylerde diğer parametreler olan karıştırma süresi, karıştırma hızı ve reaktif miktarı sırasıyla $2.5 \mathrm{dk}, 150 \mathrm{~d} / \mathrm{dk}$ ve $676 \mathrm{~g} /$ ton olarak sabit tutulmuştur. Şekil 3(d) grafiği incelendiğinde bütün $\mathrm{pH}$ değerlerinde çökme süresinin artışına bağlı olarak türbidite değerlerinin düştüğü belirlenmiştir. pH 9 da yapılan deneylerde ise ilk $30 \mathrm{dk}$ 'lık çökme süresi için en düşük türbidite değeri elde edilirken çökme süresinin artışı ile doğal pH'da yapılan deney sonuçlarının da pH 9'da elde edilen sonuçlara ulaştığı tespit edilmiştir. Tüm bu sonuçlar 1şı̆̆ında optimum deney şartlarının; $2.5 \mathrm{dk}$ karıştırma süresi, $150 \mathrm{devir} / \mathrm{dk}$ karıştırma hızı, $676 \mathrm{~g} /$ ton reaktif miktarı ve doğal $\mathrm{pH}(7.56)$ olduğu tespit edilmiştir. Bu koşullarda yapılan deney ile süspansiyonun türbiditesi başlangıç değeri olan 566 NTU'dan 34 NTU değerine \%93.99 koagülasyon verimi ile düşürülmüştür.

Şekil 4'de konvansiyonel koagülasyon deneylerinde kullanılan 3 farklı koagülantın optimum koşullarda yapılan deneylerinden elde edilen türbidite değerleri karşılaştırılmıştır.

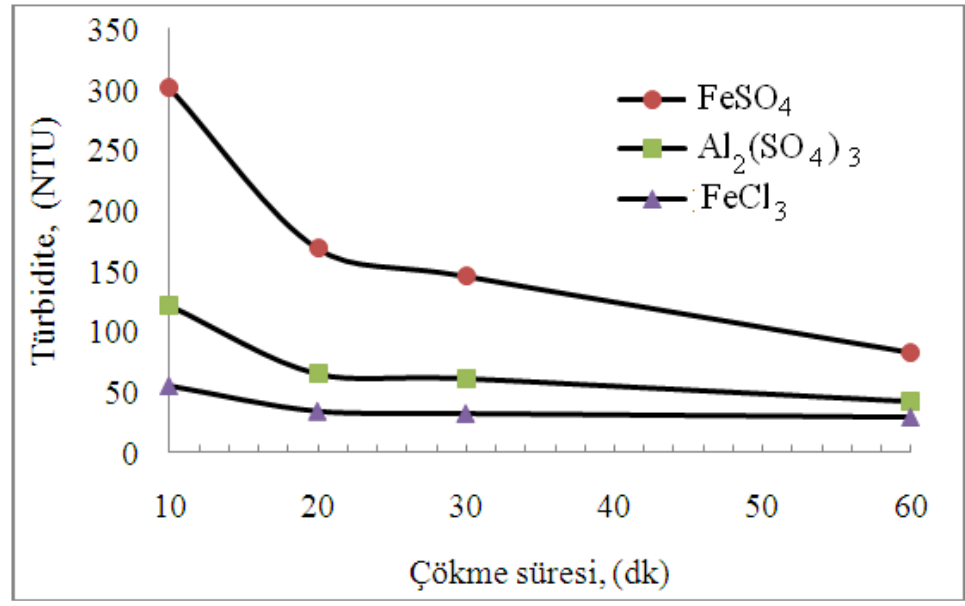

Şekil 4: Üç farklı koagülant ile yapılan deneylerin türbidite değerleri

Şekil 4'de görüldüğü gibi lavvar tesisi kömür artıkları üzerinde; demir sülfat, alüminyum sülfat ve demir klorür gibi reaktifler ile değişik şartlarda gerçekleştirilen bir dizi koagülasyon deneyleri sonucunda, demir klorürün diğer reaktiflere göre daha düşük türbidite değerleri verdiği görülmüştür. 


\section{Sonuçlar ve tartışma}

Koagülasyon deneyleri sonucunda süspansiyonun pH'sı ve reaktif miktarı koagülasyonu etkileyen iki önemli parametre olarak ortaya çıkmaktadır. Süspansiyondan kömür artıklarının uzaklaştırılmasında optimum $\mathrm{pH}$ değerleri alüminyum sülfat için 7.56(doğal $\mathrm{pH}$ ), demir sülfat için 7.65(doğal pH) ve demir klorür için 7.56(doğal pH) olarak belirlenmiştir. Bu durum literatürde Bentli ve arkadaşarının yaptığ 1 bir çalışmada elde ettiği genellikle kömür atıklarının çöktürülmesinde doğal pH'da çökme hızının maksimuma çıktığı sonucuyla uyumludur. Cengiz ve arkadaşları kömür atıkları üzerine yaptıkları flokülasyon çalışmalarında düşük karıştırma hızlarında yerçekimi kuvvetinin tanelerin çökelmesinde daha etkin olduğunu belirtmişlerdir ki bu da bizim çalışmamızda bulduğumuz değerler ile uymludur. Optimum reaktif miktarları da sirasıyla $1890 \mathrm{~g} / \mathrm{ton}$, $556 \mathrm{~g} / \mathrm{ton}$, ve $676 \mathrm{~g} / \mathrm{ton}$ olarak tespit edilmiștir. Elde edilen türbidite uzaklaştırma verimleride sirasıyla \%88.71, \%85 ve \%94 olarak gerçekleşmiştir. Deneylerde kullanılan koagülantların tüketim miktarları dikkate alınarak yapılan maliyet analizlerinde ise alimünyum sülfat için için $78.75 \mathrm{TL} /$ ton artık, demir sülfat için 20.75 $\mathrm{TL} /$ ton artık ve demir klorür için $21.86 \mathrm{TL} /$ ton artık olarak hesaplanmıştır. Verim ve maliyet değerleri birlikte değerlendirildiğinde ise demir klorürün en iyi sonuçları verdiği tespit edilmiştir.

\section{Teșekkür}

$\mathrm{Bu}$ çalışma İstanbul Üniversitesi Bilimsel Araştırmalar Birimi tarafından desteklenmiştir (Proje No: 28767).

\section{Kaynaklar}

[1] Hacifazlioglu H., A new process for the production of medium quality fuels from coal washing plant coarse tailings, Energy Sources Part A:Recovery, Utilization and Environmental Effects , vol. 38, Issue 19, 2809-2815, (2016).

[2] Das B., Prakash S., Biswal S.K., and Reddy P.S.R., "Settling characteristics of coal washery tailings using synthetic polyelectrolytes with fine magnetite, The Journal of the Southern African Institute of Mining and Metallurgy, vol. 106, 707-716, (2006).

[3] Hassas B.Z., Karakas F., Celik M. S., Ultrafine coal dewatering: Relationship between hydrophilic lipophilic balance (HLB) of surfactants and coal rank, International Journal of Mineral Processing, vol.133, 97-104,(2014).

[4] Sabah E., Erkan Z.E., Interaction mechanism of flocculants with coal waste slurry. Fuel, vol.85(3), 350-359,(2006).

[5] Jiang J. Q., The role of coagulation in water treatment, Chemical Engineering, vol.8, 36-44,(2015).

[6] Sabah E., Yuzer H., and Celık M.S., Characterization and dewatering of fine coal tailings by dual-flocculant systems. International Journal of Mineral Processing, vol.74 (1), 303-315,(2004).

[7] Bentli İ., Kömür lavvar tesisi atıkların flokülasyonunda inorganik elektrolitlerin etkisi, Ekoloji, vol.19, Issue:76, 71-77,(2010).

[8] Alam N., Ozdemir O., Hampton M.A., Nguyen A.V., "Dewatering of coal plant tailings: Flocculation followed by filtration”, Fuel, 90, 26-35,(2011).

[9] Zhang Z., Liu J., and Wang Y., Evaluation of settling characteristics of coal tailings, Proceedings, XXVI IMPC, 6025-6031,(2012). 